\title{
Counteraction to information influence in social networking services by means of fuzzy logic system
}

\section{Kateryna Molodetska ${ }^{1}$, Vladyslav Solonnikov ${ }^{2}$, Oleksandr Voitko ${ }^{3}$, Ihor Humeniuk ${ }^{4}$,} Oleksandr Matsko ${ }^{5}$, Oleksii Samchyshyn ${ }^{6}$

${ }^{1}$ Department of Computer Technologies and Systems Modeling, Zhytomyr National Agroecological University, Ukraine ${ }^{2}$ Institute for the Provision of Forces (Forces) and Information Technologies, the National Defence University of Ukraine named after Ivan Cherniakhovskyi, Ukraine

${ }^{3}$ Department Information Technologies Employment and Information Security, Institute for the Provision of Forces (Forces) and Information Technologies, the National Defence University of Ukraine named after Ivan Cherniakhovskyi, Ukraine

${ }^{4,6}$ Information Protection and Cybersecurity Department in Korolov Zhytomyr Military Institute, Ukraine ${ }^{5}$ Institute of the Troops (Forces) Support and Information Technologies in the National Defence University of Ukraine named after Ivan Cherniakhovskyi, Ukraine

\section{Article Info}

Article history:

Received Aug 17, 2020

Revised Sep 15, 2020

Accepted Dec 5, 2020

\section{Keywords:}

Actor

Decision making

Information influence

Information security of the state

Synergetic management

\begin{abstract}
The article describes a decision support system based on fuzzy inference aimed to automate the procedure of choosing a model of formalizing the interaction between actors in virtual communities of social networking services and synergistic management of such processes. The developed system aims to increase the effectiveness of counteracting threats to information security of the state in social networking services. The mathematical apparatus of the fuzzy set theory and the Mamdani algorithm are the basis for the functioning of the decision support system. The usage of the developed fuzzy inference system will remove the ambiguity of information security expertise in the course of choosing approaches to formalization and the model of synergistic management of actors' interaction in the conditions of incomplete information and ambiguous assessment of the state information security threat in social networking services.
\end{abstract}

This is an open access article under the CC BY-SA license.

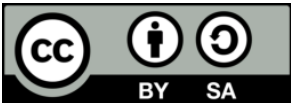

\section{Corresponding Author:}

Kateryna Molodetska

Department of Computer Technologies and Systems Modeling

Zhytomyr National Agroecological University

7, Staryy Blvd., 10008, Zhytomyr, Ukraine

Email: kmolodetska@gmail.com

\section{INTRODUCTION}

As a result of the simultaneous progress of information technology and socio-cultural changes in society, a reorientation of social communication channels has happened. This led to an increase in the number of users of social networking services (SNSs), who are commonly called actors [1-3]. Currently, SNSs are expanding their functional characteristics and are used by actors for group interaction based on common interests, self-education, coordination in real life and doing business [4-7]. However, the communicative advantages of SNSs are used by malicious users to achieve unilateral advantages in the information space, and later-on the international geopolitical arena. Such phenomena have become possible due to the dissemination of destructive content during the information operations in SNSs, which are aimed at forming a distorted reality in the minds of citizens [8-13]. Therefore, the problem of ensuring the information security of the state in SNSs is urgent and needs to be solved. 
The study proves [11] that SNSs belong to the class of complex dynamic systems, and the interaction of actors in virtual communities can be transformed into chaotic dynamics. The consequences of such behavior of virtual communities of actors in SNSs can have uncontrolled destructive information impact on users of services as well as the reflection of such processes on the life of modern society. In particular, it can lead to mass protests of citizens, the radicalization of the society based on religious, ethnic, national and political grounds. The examples of "Colorful Revolutions" in the CIS together with "The Arab Spring" in the Middle East and North Africa demonstrate that achieving a reduction in the level of radicalization of society using existing legal mechanisms is a very challenging task [14-16]. In most cases, such events led not only to civil protests but also to the overthrow of governments, their change, civil wars and armed conflicts. The most effective way to counteract the chaos of society is the timely detection of information operations in SNSs, which are conducted by the opposing party. Methods of identifying and assessing threats to information security of the state should be applied in such cases [14].

A critical analysis of the existing research works $[14,17,18]$ showed that one of the promising areas of suppression of the chaotic dynamics in the processes of actors interaction in SNSs is the usage of synergetic management. At the same time, as a result of the controlled informational influence, the selforganization processes of actors in SNSs are launched in the form of a change in the structure of virtual communities and the formation of new connections between actors. In consequence, actors begin to use the content with a certain narrative and refocus their attention on it.

Publications $[17,18]$ contain synthesized models of synergetic management of actor interaction in SNSs, and publication [14] develops a model of decision support system for identification of signs of national information security (NISec) threats in SNSs and assessment of their level. However, mentioned works do not contain practical recommendations for choosing a specific system of nonlinear differential equations and the model of synergetic management; therefore, the decision is entrusted to experts who work with the decision support system. Involving experts in the work of the decision support system at the stage of countering threats in terms of choosing a model of synergetic management has several disadvantages. For instance: increasing the level of subjectivity, the inertia of the decision-making process, high level of requirements for expert knowledge. Reduction of the negative impact of such factors is achieved through the usage of decision-making methods without experts being involved.

The problem of choosing a model of synergetic management is to determine the parameters of a complex dynamic social system, which must be managed to achieve this goal. According to the results of previous research, it is advisable to influence the demand of actors for content on certain topics. Changing the level of demand for content is achieved by encouraging the interest of actors, by varying the parameters of regularization of supply and demand, as well as artificial influence on the speed of distribution of this content or content similar in essence and content. As a result of the implementation of such synergetic management in the SIS, the processes of self-organization of actors into virtual communities are launched. Such associations of actors independently regulate the distribution of content as a result of social control on the basis of social norms and sanctions. As a result, the managed community is capable of self-development through the voluntary publication of content on a given topic, the involvement of new participants and a critical perception of destructive content.

The developed mathematical models of synergetic control are presented in publications [14, 17, 18]. A comparative analysis of such models showed that they differ in the mechanisms of synthesis management (publication of refutations of misinformation, dissemination of other popular content to refocus the attention of actors, re-publication of given topics to accelerate the reduction of interest in it). Also, the synthesized models differ in their impact on actors in terms of the dynamics of changes in demand for content-ascending or descending. Therefore, the problem of choosing an effective model of synergetic management for a specific information operation carried out by attackers, taking into account its characteristics, remains relevant.

Taking into consideration the contradictory requirements while choosing a model of synergetic management, ambiguity in assessing the level of NISec threats in SNSs, the difficulty of determining priorities, lack of generally accepted rules for formalizing the interaction of actors in virtual communities and synergetic management, decision-making procedures are becoming more complex. Therefore, an effective way to eliminate the difficulties is to use the mathematical apparatus of fuzzy sets [19-22]. Development of a model of a decision support system based on a fuzzy inference is promising. Such systems combine the basic statements of the theory of fuzzy sets and allow solving issues related to decision-making on weakly structured and complexly formalized study objects. Thus, the development of the decision support system model for managing the actors interaction in SNS will ensure the effective transition of the virtual community to a given state of NISec. It will additionally update the chosen direction of current research. Our work aims to increase the effectiveness of countermeasures to the NISec threats in SNS y means of development of timely and effective recommendations for managing the actors' interaction in virtual communities by the decision support system.

Counteraction to information influence in social networking services by means of... (Kateryna Molodetska) 


\section{RESEARCH METHOD}

\subsection{The structure of the decision support system}

Fuzzy inference systems are a partial case of fuzzy systems, the operation of which is based on the conditions and conclusion on their basis. At the same time, the rules are formalized in the form of statements (productions) regarding a set of input and output fuzzy linguistic variables. The generalized structural scheme of the decision support system for managing the interaction of actors in SNSs is presented in Figure 1. The decision support system for managing the actors' interaction in SNSs [23] includes the modules:

- A fuzzification module for fuzzy inclusion within the process of the description of the parameters of SNSs information space with the usage of the mathematical apparatus of fuzzy sets

- A database containing the information on the management of the parameters of actors' interaction in virtual communities, obtained from experts in the form of production rules

- A base of synergetic management models, which includes formalized processes of actors interaction in the information space and corresponding synthesized models of synergetic management, which will ensure the transition of the virtual community to a given state of information security

- A solver module for converting input fuzzy variables to output with the help of a database and the base of synergetic management models of the actors' interaction

- A defuzzification module that provides an inverse transition from fuzzy sets to normal values for decision making.

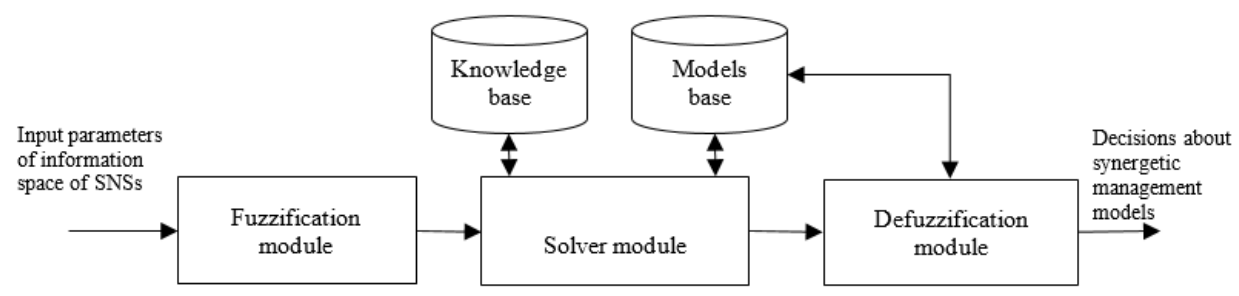

Figure 1. Block diagram of the decision support system based on fuzzy inference

\subsection{Qualitative indicators to characterize the interaction of actors in SNSs}

To counter NISec threats in SNSs effectively, the primary aim is to define a mathematical model for formalizing the interaction of actors, and then we can directly choose a model of synergetic management, which will enable an artificially controlled transition to a given state of interaction parameters in the information space of services. The choice should be made in accordance with the characteristics of the information space of SNSs, which describe the peculiarities of the implementation of threats related to information security of the state. Therefore, the procedure of selecting models of synergetic management by experts is described by the decision making tree, which is presented in Figure 2.

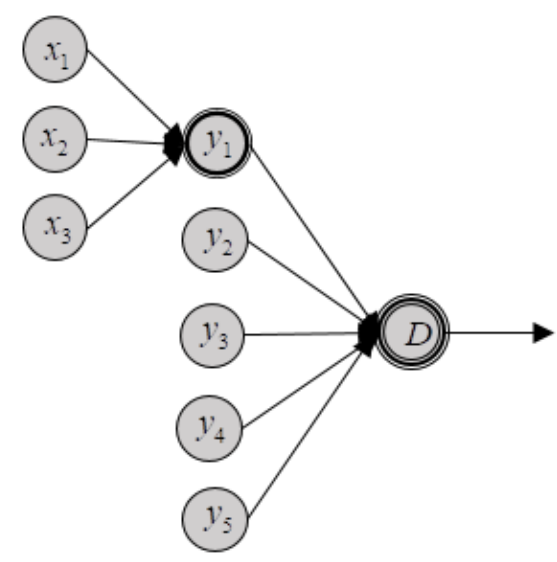

Figure 2. Tree of decisions on the management of the interaction of actors 
The indicators that determine the approach to the formalization of the actors interaction in the form of a system of nonlinear differential equations and directly synergetic management models are:

$x_{1}-$ The level of confrontation of actors in virtual communities

$x_{2}$ - The involvement of external information resources for the implementation of threats in SNSs

$x_{3}$ - The level of influence of the narrative spread by the malefactors on the formation of public opinion on certain issues among actors

$y_{1}$ - Recommended model of actors' interaction in SNSs

$y_{2}$ - The level of actors' demand for destructive content

$y_{3}$ - The supply level of destructive content in the information space of services

$y_{4}$ - The duration of the information campaign in the information space of the services

$y_{5}$ - The intensity of changes in the operational situation in the information space of SNSs.

The initial variable of the system is $D$ - the decision on the choice of the synergetic management models which are developed in the publications $[14,17,18]$. The interdependence of the chosen indicators for the qualitative characteristic of actors`interaction can be presented as a system of relations.

$$
\begin{aligned}
& y_{1}=f\left(x_{1}, x_{2}, x_{3}\right) \\
& D=f\left(y_{1}, y_{2}, y_{3}, y_{4}, y_{5}\right)
\end{aligned}
$$

The input and output variables of the fuzzy inference system acquire values defined by their universal sets and are estimated by fuzzy terms according to Table 1.

Table 1. Linguistic terms of variable systems of fuzzy inference

\begin{tabular}{ccc}
\hline Fuzzy variable & Universal set of fuzzy variable & Linguistic variable \\
\hline$x_{1}$ & {$[0 ; 1]$} & Low (L); Medium (M); High Medium (HM); High (H) \\
$x_{2}$ & {$[0 ; 1]$} & Low (L); Medium (M); High Medium (HM); High (H) \\
$x_{3}$ & {$[0 ; 1]$} & Low (L); Medium (M); High Medium (HM); High (H) \\
$y_{1}$ & {$[0 ; 1]$} & Predator-prey interaction model (IM1); Mono model (IM2) \\
$y_{2}$ & {$[0 ; 1]$} & Low (L); Medium (M); High Medium (HM); High (H) \\
$y_{3}$ & {$[0 ; 1]$} & Low (L); Medium (M); High Medium (HM); High (H) \\
$y_{4}$ & {$[0 ; 1]$} & Small (S); Medium (M); Large (L); XLarge (XL) \\
$y_{5}$ & {$[0 ; 1]$} & Low (L); Medium (M); High Medium (HM); High (H) \\
$D$ & {$[0 ; 1]$} & Model of synergetic demand management (M1); model of synergetic \\
& & maintenance of a given level of demand (M2); model of forming a \\
\end{tabular}

\subsection{Fuzzy production rules in the decision support system}

Fuzzy production rules presented in Table 2 were formulated in the form of statements that combine linguistic variable systems of expressions (1)-(2). For convenience, there is only a fragment of the database, which was formulated with the participation of experts.

\subsection{Operation algorithm of the decision support system for managing the interaction of actors in SNSs}

Currently, there are a number of fuzzy inference algorithms, the most common of which is the Mamdani and Sugeno algorithm [24-27]. The first of the kind is used in the case of problem-solving for which the critical factor is the explanation and justification of the decision. In turn, the Sugeno algorithm is characterized by the adaptation to solvfing identification problems. Therefore, to implement a fuzzy inference system to select a model of synergistic management of actors' interaction in SNSs, we will use the Mamdani algorithm. The essence of Mamdani algorithm for the decision-making task on the choice of synergetic management model is reduced to the steps [28]:

Step 1. Fuzzyfication of the input variables of the system $X=\left\{x_{1}\right\}$, where $i=\overline{1,3}$ and the output variable is $Y_{1}=\left\{y_{1}\right\}$. To do this, we use an S-shaped increasing function $\mu_{1}\left(x_{i}\right)$, two models of a U-shaped function $\mu_{2}\left(x_{i}\right), \mu_{3}\left(x_{i}\right)$ and an S-shaped descending one $\mu_{4}\left(x_{i}\right)$ [9]. Fuzzification of the remaining input and output linguistic variables of the decision support system is performed similarly.

Counteraction to information influence in social networking services by means of... (Kateryna Molodetska) 
Step 2. The aggregation of subconditions in fuzzy production rules presented in Table 2 is reduced to finding the degree of truthfulness for the conditions of each rule of the pre-formed database using the logical operations. In this case, operations AND or OR are replaced to the conjunction $(\wedge)$ or disjunction $(\vee)$ by means of maximization or minimization operations, respectively.

Step 3. The activation of the subconclusion in the database rules, which is performed using the minactivation method according to which

$$
\mu_{j}\left(x_{i}\right)=\min \left\{n_{m}, \mu_{j}\left(x_{i}\right)\right\},
$$

where $n_{m}$ determines the truth of a particular rule of the database. At the same time, inactive database rules are not taken into account in order to reduce data processing time.

Step 4. Accumulation of the conclusions of fuzzy production rules is carried out for association of those fuzzy sets which correspond to terms of subconclusions concerning the same initial variables

$$
\mu\left(y_{1}\right)=\max \left\{\mu_{y_{1}}\left(x_{1}, x_{2}, x_{3}\right)\right\}
$$

Step 5. Defuzzification of the output variable $y_{1}$ is performed according to the plane centre method for which

$$
\int_{\min }^{u} \mu\left(x_{i}\right) d x=\int_{u}^{\max } \mu\left(x_{i}\right) d x .
$$

The algorithm describes the fuzzy inference procedure for functional dependence (2). To implement the functional relationship in the decision support system (1), it is necessary to perform similar steps 1-5 for the input variables $Y=\left\{y_{k}\right\}, k=\overline{1,5}$ and the output variable $D=\{d\}$.

Table 2. Fragment of the system rule base

\begin{tabular}{cccc}
\hline$x_{1}$ & $x_{2}$ & $x_{3}$ & $y_{1}$ \\
\hline H & H & H & IM1 \\
H & HM & HM & IM1 \\
H & M & L & IM1 \\
HM & H & HM & IM1 \\
HM & HM & L & IM1 \\
HM & M & M & IM1 \\
HM & L & M & IM2 \\
HM & L & L & IM2 \\
M & HM & M & IM1 \\
M & M & M & IM1 \\
M & L & H & IM2 \\
M & L & M & IM2 \\
L & H & M & IM2 \\
L & HM & H & IM2 \\
L & M & M & IM2 \\
L & L & L & IM2 \\
\hline
\end{tabular}

\section{RESULTS AND DISCUSSION}

\subsection{Model of the decision support system for managing the interaction of actors in SNSs}

Let us study the developed model of the decision support system for managing the interaction of actors in SNSs using the fuzzy logic environment of the MATLAB application package. To do this, consider the example of an information operation in SNSs, aimed at forming a negative public opinion in society concerning Ukraine's accession to NATO. The input data for the decision support system for managing the interaction of actors in SNSs are expert assessments of the Department of Information Protection and Cybersecurity of Zhytomyr Military Institute named after S.P. Korolyov in Table 3. Data were obtained based on public opinion data in Ukraine on Euro-Atlantic integration in 2019 and summarized information about the information campaigns in SNSs, aimed at the freedom of choice of citizens. The expected forms of the first step results of the Mamdani algorithm for the linguistic variable $x_{1}$ are given in Figure 3 . The 
developed rule base of the decision support system, which describes the dependence (2), loaded into the fuzzy logic environment, is shown in Figure 4. A fragment of the accumulation results of conclusions of fuzzy production rules for the system of relations (2) in the fuzzy logic environment is presented in Figure 5. The results of the defuzzification of the initial variable $d$ of the decision support system is shown in Figure 6.

Table 3. Set of input data for the decision support system

\begin{tabular}{cccccccc}
\hline & $x_{1}$ & $x_{2}$ & $x_{3}$ & $y_{2}$ & $y_{3}$ & $y_{4}$ & $y_{5}$ \\
\hline Meaning & 0,6 & 0,8 & 0,6 & 0,2 & 0,7 & 0,3 & 0,5 \\
\hline
\end{tabular}

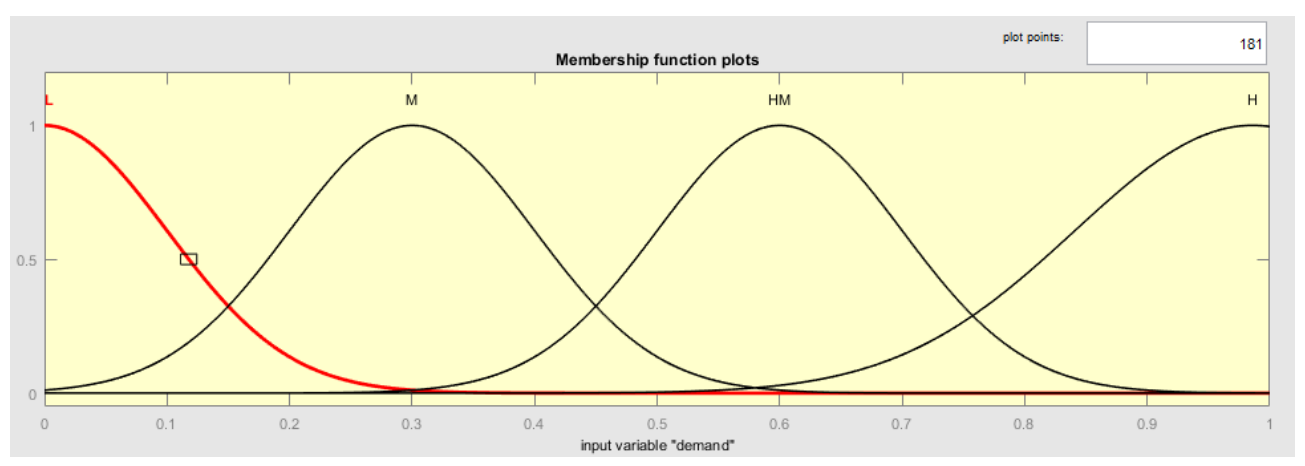

Figure 3. The membership functions graphs of a linguistic variable $x_{1}$
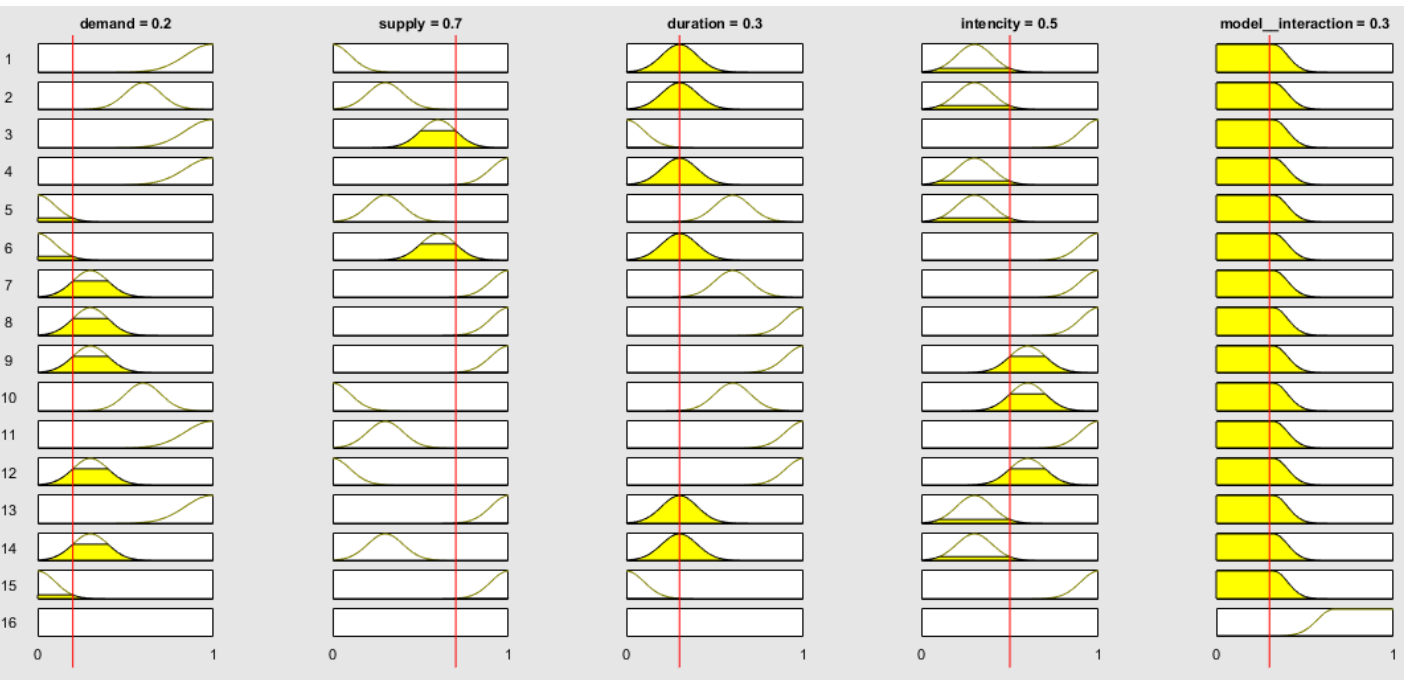

Figure 5. Rule editor after the fuzzy conclusion 


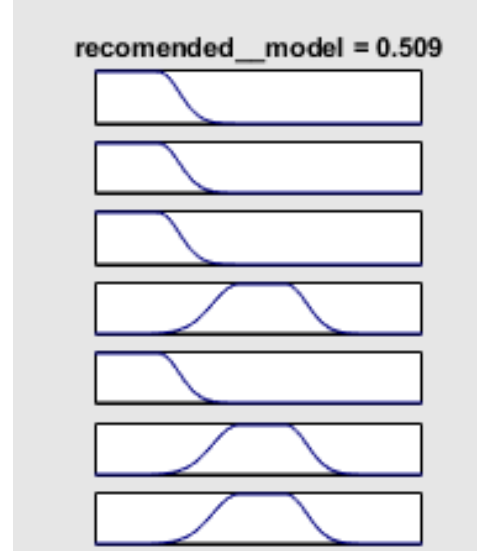

Figure 6. The results of a fuzzy conclusion

Therefore, to counteract the considered threat to information security in SNSs, it is necessary to apply the M2 model of synergistic support of a given demand level for certain content [17]. To do this, it is necessary to publish the number of posts specified in accordance with this model in SNS information space. To visualize the dependence of the output variable $d$ on the values of the input $y_{2}$ and $y_{5}$ a three-dimensional surface needs to be constructed as shown in Figure 7. The given surface in Figure 7 can be used for further improving the decision-making process in order to increase the level of their adequacy for different values of the threat level to national information security in SNSs.

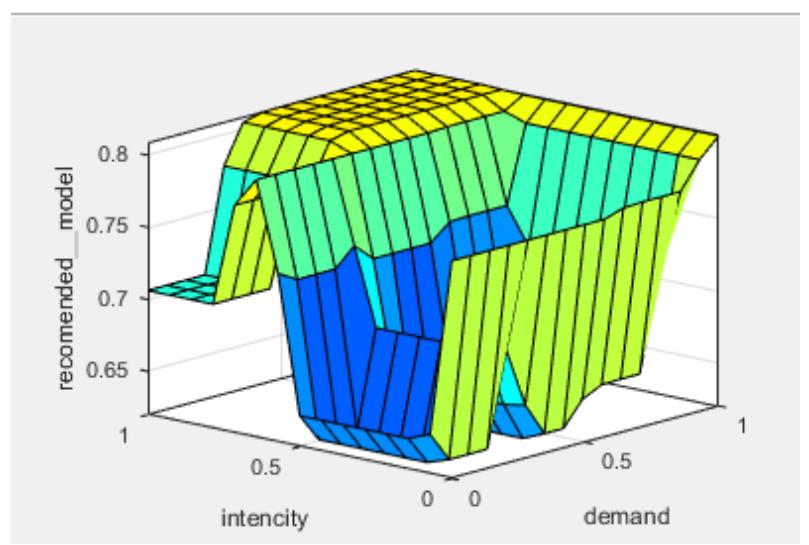

Figure 7. The surface of a fuzzy inference

\subsection{Discussion of results}

The analysis of the obtained results of information counteraction to destructive informational influence with the use of the developed model of the fuzzy logical conclusion system allowed to make the conclusions:

- The developed hierarchical system of interrelated indicators $X=\left\{x_{i}\right\}, Y=\left\{y_{k}\right\}$ allows taking into account the peculiarities of the conducted informational operation in SNSs. Such indicators have been formed taking into consideration the results of critical analysis of numerous information operations that took place in the information space of SNSs. Under the circumstances of the constant appearance of new approaches to the conduction of information actions by attackers in SNSs, the proposed indicators allow to identify the information operation, assess its impact on actors and virtual communities, and are also used for further decision-making concerning efficient counteraction to such threats to information security.

- The proposed model of the fuzzy inference system allows deciding on the choice of a specific model of synergetic management. Based on the selected model, the dynamics of publications of a given content in 
SNSs is determined to counteract the destructive informational impact. As a result of the dissemination of such messages, actors self-organize into virtual communities that are capable of developing and creating the new content independently. This is the way the threats posed by the spread of destructive content in SNSs are counteracted.

- Increase of the effectiveness of countering threats in SNSs is achieved by the reduction the degree of subjectivity of decisions, reduction of the duration of the procedure of their adoption by experts and increasing the efficiency of countermeasures. This effect is achieved through the implementation and usage of the software based on the developed model of decision support system.

- Conducted experimental studies of the developed system of fuzzy inference showed that due to the application of the recommended model of synergetic management, the reduction of interest in publications that had a destructive information impact on public opinion happens $30 \%$ faster than without its application.

- The proposed system of fuzzy inference can be improved in accordance with the rapid change in the nature of informational operations in SNSs, technologies for their implementation, the emergence of new narratives in the information space of services. by means of filling with the new models of synergetic management to counter the threats and knowledge base rules.

\section{CONCLUSION}

As a result of the conducted research, for the first time, the model of a decision support system for managing the actors' interaction in SNSs was introduced. The basis of the described model is a fuzzy logic conclusion. This approach provides an increase in the degree of decision validity on the model choice for formalizing the actors' interaction in virtual communities and the corresponding model of synergistic counteraction to information security threats in SNSs. Mamdani algorithm was chosen to reduce the degree of uncertainty in decision-making by a NISec expert on the functioning of the decision support system.

We have developed the structure of the system, have defined input and output linguistic variables. Moreover, to reflect the relationship between the variables a hierarchical tree of decisions has been built, a database in the form of rules of fuzzy production rules has been formed. Also, we have constructed the model of the decision support system based on the fuzzy derivation of the MATLAB fuzzy logic environment. An example of its application using the data on the impact of destructive information on SNS actors to form a negative public opinion about Ukraine's Euro-Atlantic integration was used. The advantage of the developed model of the system is the ability to scale and their supplement with new models of actors' interaction and synergetic management of interaction in virtual communities.

\section{REFERENCES}

[1] U. Can and B. Alatas, "A new direction in social network analysis: Online social network analysis problems and applications," Physica A: Statistical Mechanics and its Applications, vol. 535, pp-1-38, 2019, doi: 10.1016/j.physa.2019.122372.

[2] W. K. Lai, Y. U. Chen, and T. Y. Wu, "Analysis and evaluation of random-based message propagation models on the social networks," Computer Networks, vol. 170, pp. 1-14, 2020, doi: 10.1016/j.comnet.2019.107047.

[3] Y. Guo, Z. Lu, H. Kuang, and C. Wang, "Information avoidance behaviour on social network sites: Information irrelevance, overload, and the moderating role of time pressure," International Journal of Information Management, pp. 1-12, 2020, doi: 10.1016/j.ijinfomgt.2020.102067.

[4] K. J. Baker-Doyle and S. A. Yoon, "The social side of teacher education: Implications of social network research for the design of professional development," International Journal of Educational Research, vol. 101, pp. 1-5, 2020. Available: $10.1016 /$ j.ijer.2020.101563.

[5] K. Molodetska, Y. Brodskiy, and S. Fedushko, "Model of Assessment of Information-Psychological Influence in Social Networking Services Based on Information Insurance," Proc. 2nd International Workshop Control, Optimisation and Analytical Processing of Social Networks, 2020, vol. 2616, 2020, pp. 187-198.

[6] S. Yevseiev, V. Ponomarenko, and O. Rayevnyeva, "Assessment of functional efficiency of a corporate scientificeducational network based on the comprehensive indicators of quality of service," East European Journal of Advanced Technology, vol. 6, no. 2, pp. 4-15, 2017.

[7] M. Lombardi, A. Lopolito, A. M. Andriano, M. Prosperi, A. Stasi, and E. Iannuzzi, "Network impact of social innovation initiatives in marginalised rural communities," Social Networks, vol. 63, pp. 11-20, 2020, doi: 10.1016/j.socnet.2020.04.001.

[8] S. Rathore, P. K. Sharma, V. Loia, Y. S. Jeong, and J. H. Park, "Social network security: Issues, challenges, threats, and solutions," Information sciences, vol. 421, pp. 43-69, 2017, doi: 10.1016/j.ins.2017.08.063.

[9] R. Hryshchuk, K. Molodetska, and Y. Tymonin, "Modelling of conflict interaction of virtual communities in social networking services on an example of anti-vaccination movement," Proc. International Workshop on Conflict Management in Global Information Networks, 2019, pp. 250-264. 
[10] Z. Holub, I. Holub, and A. Peleschyshyn, "Methods of real-time detecting manipulation in online communities," in Proc. of the 11th International Scientific and Technical Conference Computer Sciences and Information Technologies, 2016, pp. 15-17, doi: 10.1109/STC-CSIT.2016.7589857.

[11] C. H. Malin, T. Gudaitis, T. J. Holt, and M. Kilger, "Asymmetric Warfare and Psyops: Nation State-Sponsored Cyber Attacks," in C. H. Malin, T. Gudaitis, T. J. Holt, M. Kilger (eds), Deception in the Digital Age. Academic Press, pp. 207-226, 2017.

[12] M. Aldwairi and A. Alwahedi, "Detecting fake news in social media networks," Procedia Computer Science, vol. 141, pp. 215-222, 2018, doi: 10.1016/j.procs.2018.10.171.

[13] G. Saridakis, V. Benson, J. N. Ezingeard, and H. Tennakoon, "Individual information security, user behaviour and cyber victimisation: An empirical study of social networking users," Technological Forecasting and Social Change, vol. 102, pp. 320-330, 2016, doi: 10.1016/j.techfore.2015.08.012.

[14] R. Hryshchuk and K. Molodetska-Hrynhchuk, "Methodological Foundation of State's Information Security in Social Networking Services in Conditions of Hybrid War," Information and Security: An International Journal, vol. 41, pp. 55-73, 2018, doi: 10.11610/isij.4105.

[15] R. Klischewski, "When virtual reality meets realpolitik: Social media shaping the Arab government-citizen relationship," Government Information Quarterly, vol. 31, no. 3, pp. 358-364, 2014, doi: 10.1016/j.giq.2013.10.015.

[16] M. Ali, N. Azab, M. K. Sorour, and M. Dora, "Integration v. polarisation among social media users: Perspectives through social capital theory on the recent Egyptian political landscape," Technological Forecasting and Social Change, vol. 145, pp. 461-473, 2019, doi: 10.1016/j.techfore.2019.01.001.

[17] R. Hryshchuk and K. Molodetska, "Synergetic Control of Social Networking Services Actors' Interactions," in Recent Advances In Systems, Control And Information Technology, vol. 543, pp. 34-42, 2017, doi: 10.1007/9783-319-48923-0_5.

[18] R. Hryshchuk, K. Molodetska, and Y. Serov, "Method of improving the information security of virtual communities in social networking services," Proc. of the 1st International Workshop on Control, Optimisation and Analytical Processing of Social Networks, vol. 2392, 2019, pp. 23-41.

[19] B. Wu, T. Cheng, T. L. Yip, and Y. Wang, "Fuzzy logic based dynamic decision-making system for intelligent navigation strategy within inland traffic separation schemes," Ocean Engineering, vol. 197, p. 106909, 2020, doi: 10.1016/j.oceaneng.2019.106909.

[20] F. Fan and G. Wang, "Fuzzy logic interpretation of quadratic networks," Neurocomputing, vol. 374, pp. 10-21, 2020, doi: 10.1016/j.neucom.2019.09.001.

[21] J. G. Dan, J. Arnaldos, and R. M. Darbra, "Introduction of the human factor in the estimation of accident frequencies through fuzzy logic," Safety science, vol. 97, pp. 134-143, 2017, doi: 10.1016/j.ssci.2015.08.012.

[22] N. Marín, G. Rivas-Gervilla, D. Sánchez, and R. R. Yager, "Specificity measures based on fuzzy set similarity," Fuzzy Sets and Systems, vol. 401, pp. 189-199, 2019, doi: 10.1016/j.fss.2019.06.001.

[23] A. V. Leonenkov, Fuzzy modeling in MATLAB and fuzzyTECH, [in Russian]. BHV-Peterburg, Sankt-Peterburg, Russia, 2005.

[24] K. Belarbi, F. Titel, W. Bourebia, and K. Benmahammed, "Design of Mamdani fuzzy logic controllers with rule base minimisation using genetic algorithm," Engineering applications of artificial intelligence, vol. 18, no. 7, pp. 875-880, 2005, doi: 10.1016/j.engappai.2005.03.003.

[25] F. M. Innocent and A. Y. U. Gital, "Dr. Flynxz-A First Aid Mamdani-Sugeno-type Fuzzy Expert System for Differential Symptoms-Based Diagnosis," Journal of King Saud University-Computer and Information Sciences, 2020, doi: 10.1016/j.jksuci.2020.04.016.

[26] M. H. Qais, H. M. Hasanien, and S. Alghuwainem, "Whale optimization algorithm-based Sugeno fuzzy logic controller for fault ride-through improvement of grid-connected variable speed wind generators," Engineering Applications of Artificial Intelligence, vol. 87, p. 103328, 2020, doi: 10.1016/j.engappai.2019.103328.

[27] Q. Brabant, M. Couceiro, D. Dubois, H. Prade, and A. Rico, "Learning rule sets and Sugeno integrals for monotonic classification problems," Fuzzy Sets and Systems, 2020, doi: 10.1016/j.fss.2020.01.006.

[28] A. Akgun, E. A. Sezer, H. A. Nefeslioglu, C. Gokceoglu, and B. Pradhan, "An easy-to-use MATLAB program (MamLand) for the assessment of landslide susceptibility using a Mamdani fuzzy algorithm," Computers \& Geosciences, vol. 38, no. 1, pp. 23-34, 2012.

\section{BIOGRAPHIES OF AUTHORS}

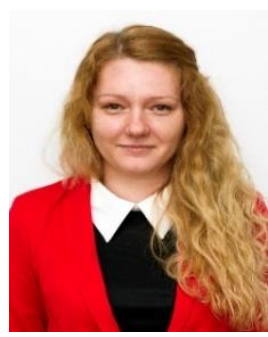

Kateryna Molodetska (1985), Doctor of Technical Sciences, Associate Professor, Professor of Computer Technology and Modeling Systems Department in Zhytomyr National Agroecological University. Graduated with honors from Zhytomyr Military Institute named after S. P. Korolyov. Studied at the postgraduate school of the Department of Hybrid Control and Modeling Systems in the Energy Institute of the Problems of Modeling in the Power Engineering named after G. E. Pukhov in the National Academy of Sciences of Ukraine. The sphere of scientific interests is connected with mathematical modeling and information security. 

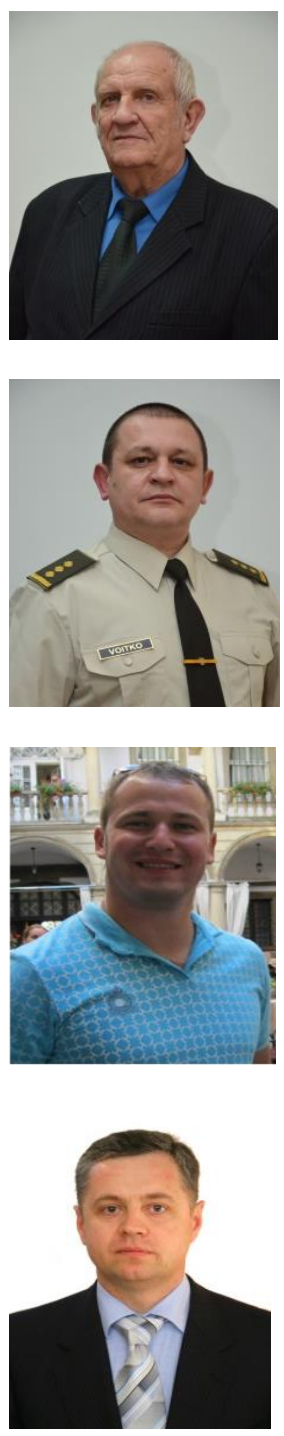

Oleksandr Matsko (1963), Candidate of Science (Military), Professor, Chief of Institute of the Troops (Forces) Support and Information Technologies in the National Defence University of Ukraine named after Ivan Cherniakhovskyi. Graduated from Kamenets-Podolsky Higher Military Command and Engineering School. Studied at the Military-Engineering Faculty of Kamenets-Podolsky agricultural Institute. Studied at the postgraduate school of the National Defence University of Ukraine. Studied at the National Defence University of Ukraine (strategic level). The sphere of scientific interests is connected with engineering (physical and mathematical modeling, information technologies).

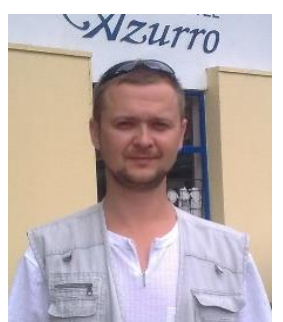

Vladyslav Solonnikov (1941), Doctor of Technical Sciences, Professor, Leading Scientific Worker the Institute for the provision of forces (forces) and information technologies, the National Defence University of Ukraine named after Ivan Cherniakhovskyi. Honored Master of Science and Technology of Ukraine. Academician of the Aerospace Academy of Ukraine. The sphere of scientific is military cybernetics, information science, systems analysis, operation research, weaponization and military equipment.

Oleksandr Voitko (1976), Candidate of Military Sciences, Deputy chief of the department information technologies employment and information security, the Institute for the provision of forces (forces) and information technologies, the National Defence University of Ukraine named after Ivan Cherniakhovskyi. Grant holder of the Presidential Academic Scholarship for Distinction in Science and Research. The sphere of scientific is strategic communications, information confrontation, information systems

Ihor Humeniuk (1988), Candidate of Technical Sciences, Senior Lecturer of Information Protection and Cybersecurity Department in Korolov Zhytomyr Military Institute. Graduated with honors from Korolov Zhytomyr Military Institute of National Aviation University. Studied at the postgraduate school of the Department of Computer Integrated Technologies in the Korolov Zhytomyr Military Institute. The sphere of scientific interests is connected with computer networks and components, information and cyber security.

Oleksii Samchyshyn (1979), Candidate of Technical Sciences (PhD), Professor of Information Protection and Cybersecurity Department in Korolov Zhytomyr Military Institute. Graduated with honors from Zhytomyr Military Institute named after S. P. Korolyov. Studied at the postgraduate school of the Korolov Zhytomyr Military Institute. The sphere of scientific interests is connected with information security systems, information and cyber security. 